\title{
Altered glycolysis results in drug-resistant in clinical tumor therapy (Review)
}

\author{
JINGHUI PENG $^{1 *}$, YANGYANG CUI ${ }^{1 *}$, SHIPENG XU $^{2}$, XIAOWEI WU ${ }^{1}$, YUE HUANG $^{1}$, \\ WENBIN ZHOU ${ }^{1}$, SHUI WANG ${ }^{1}$, ZIYI FU ${ }^{3,4}$ and HUI XIE ${ }^{1}$
}

\begin{abstract}
Departments of ${ }^{1}$ Breast Surgery, The First Affiliated Hospital, Nanjing Medical University, Nanjing, Jiangsu 210029, P.R. China; ${ }^{2}$ Robert H. Lurie Comprehensive Cancer Center, Northwestern University Feinberg School of Medicine, Chicago, IL 60611, USA; ${ }^{3}$ Nanjing Maternal and Child Health Medical Institute, Obstetrics and Gynecology Hospital Affiliated to Nanjing Medical University, Nanjing Maternity and Child Health Care Hospital, Nanjing, Jiangsu 210004; ${ }^{4}$ Department of Oncology, The First Affiliated Hospital, Nanjing Medical University, Nanjing, Jiangsu 210029, P.R. China
\end{abstract}

Received October 6, 2020; Accepted December 23, 2020

DOI: 10.3892/ol.2021.12630

\begin{abstract}
Cancer cells undergo metabolic reprogramming, including increased glucose metabolism, fatty acid synthesis and glutamine metabolic rates. These enhancements to three major metabolic pathways are closely associated with glycolysis, which is considered the central component of cancer cell metabolism. Increasing evidence suggests that dysfunctional glycolysis is commonly associated with drug resistance in cancer treatment, and aberrant glycolysis plays a significant role in drug-resistant cancer cells. Studies on the development of drugs targeting these abnormalities have led to improvements in the efficacy of tumor treatment. The present review discusses the changes in glycolysis targets that cause drug resistance in cancer cells, including hexokinase, pyruvate kinase, pyruvate dehydrogenase complex, glucose transporters, and lactate, as well the underlying molecular mechanisms and corresponding novel therapeutic strategies. In addition, the association between increased oxidative phosphorylation and drug resistance is introduced, which is caused by metabolic plasticity. Given that aberrant glycolysis has been identified as a common metabolic feature of drug-resistant tumor cells, targeting glycolysis may be a novel strategy to develop new drugs to benefit patients with drug-resistance.
\end{abstract}

Correspondence to: Professor Hui Xie, Department of Breast Surgery, The First Affiliated Hospital, Nanjing Medical University, 300 Guangzhou Road, Nanjing, Jiangsu 210029, P.R. China

E-mail: Hxie@njmu.edu.cn

Mr. Ziyi Fu, Department of Oncology, The First Affiliated Hospital, Nanjing Medical University, 300 Guangzhou Road, Nanjing, Jiangsu 210029, P.R. China

E-mail: fzyzzu@hotmail.com

*Contributed equally

Key words: cancer, glycolysis, drug resistance, microenvironment, metabolism

\section{Contents}

1. Introduction

2. Glycolysis-related enzymes contribute to chemotherapy resistance in cancer cells

3. Glycolysis related substrates and products play roles in chemotherapy resistance

4. Glycolysis is associated with immunotherapy resistance

5. Transition of glycolysis to OXPHOS enhances drug resistance

6. Conclusions

7. Future direction and perspectives

\section{Introduction}

Metabolic disorders, particularly those concerning glucose metabolism, play an important role in the proliferation and development of tumors (1). In normal cells, the energy provided for cell biological activity is predominantly dependent on changes in glucose metabolism that can transform glucose into pyruvate after several steps. Subsequently, pyruvate is converted to oxaloacetate, resulting in the production of citrate in the mitochondrial tricarboxylic acid cycle (TCA cycle). The process of glucose metabolism and the mitochondrial TCA cycle can generate energy in the form of adenosine triphosphate (ATP) and other forms, such as NADPH and FADH2 (1). NADPH and FADH2 are subsequently committed to the electron transport chain complexes to yield ATP, which is known as oxidative phosphorylation (OXPHOS) $(2,3)$.

There are significant differences between normal cells and tumor cells regarding glucose metabolism. Warburg suggested that glycolysis is the predominant metabolic mechanism that produces the most ATP in cancer cells, which means that pyruvate derived from glucose is converted to lactate to exert its effects instead of being incorporated into the TCA cycle (2), and this is known as 'the Warburg effect'. Subsequently, the 'reverse Warburg effect' proposed that tumor-associated fibroblasts can produce large amounts of lactic acid via aerobic glycolysis, which is provided to 
adjacent cells in a paracrine manner, causing the activation of mitochondria, increasing OXPHOS in adjacent cells and promoting tumor activity (3). Generally, 'the Warburg effect' and 'reverse Warburg effect' play an essential role in the development of cancer.

The incidence and mortality rates associated with cancer remain high, and despite the vast array of treatments available, chemotherapy resistance remains a significant challenge (4). There are several mechanisms of resistance, such as the mutation on binding sites, the activation of downstream effectors and the participation of alternative survival pathways to bypass target inhibition (5). In addition, cancer cells are resistant to immunotherapy via the Wnt- $\beta$-catenin signaling pathway, mitogen-activated protein kinase signaling pathways, cell cycle regulation signaling pathways and pathways activated based on the absence of the tumor suppressor phosphoinositide phosphatase, PTEN (6). Extensive research has been performed on glycolysis, which is considered a core process in tumor biological activity. Currently, increasing evidence suggests that that increased aerobic glycolysis is closely associated with chemotherapy resistance, even under $\mathrm{O}_{2}$-rich conditions (7). For example, lapatinib and tamoxifen can induce resistance in breast cancer cells by promoting glycolysis (8-10). However, the clinical application of glycolysis inhibition through medical approaches is limited. Thus, it is essential to re-emphasize glycolysis in cancer cells to overcome therapy resistance. The present review summarizes some of the most common targets in drug-resistant tumor cells, investigates their role in the acquisition of drug resistance, and summarizes corresponding drugs against these targets to suppress chemotherapy resistance in tumor cells.

\section{Glycolysis-related enzymes contribute to chemotherapy resistance in cancer cells}

Increasing evidence suggests that glycolysis in cancer is associated with drug resistance $(11,12)$. Aberrant expression of glycolysis-related enzymes, as regulators of glycolysis, induces glycolysis dysregulation, which contributes to tumorigenesis, tumor development and tumor therapy resistance (13).

Hexokinase (HK2). HK2 is a critical enzyme that promotes breast cancer progression and resistance via tumor glycolysis (14). HK2 blocks apoptosis by binding to the voltage-dependent anion channel (VDAC), which contributes to chemoresistance (15). Upregulation of HK2 expression can also induce chemotherapy resistance. Liu et al (14) demonstrated that by suppressing the mTOR-S6K signaling pathway, upregulation of HK2 promotes autophagy, subsequently conferring tamoxifen resistance to MCF-7 breast cancer cells.

In addition to upregulation of HK2 expression, its phosphorylation on Thr473 can also induce drug resistance. Proviral insertion in murine lymphomas 2 increases HK2 enzyme activity and enhances glycolysis by phosphorylating HK2 on Thr473, contributing to paclitaxel resistance (16). Conversely, SMI-4a can re-sensitize paclitaxel-resistant cells by dephosphorylating HK2 on Thr473 (17). In addition, an increase in $\mathrm{HK} 2$ dimers can also promote gemcitabine resistance. Fan et al (18) reported that in pancreatic cancer, reactive oxygen species (ROS) derived from gemcitabine promote HK2 dimerization and bind to VDAC, which inhibits apoptosis by suppressing the formation of mitochondrial permeability transition pores, ultimately resulting in gemcitabine resistance $(15,18)$.

Given the vital role of HK2 in tumor resistance, it can be used as a valuable target in investigating chemoresistance inhibition. HK2 inhibitor 3-bromopyruvate facilitates the dissociation of HK2 from the mitochondrial complex, potentiating daunorubicin-induced apoptosis and promoting leukemia cell sensitivity to daunorubicin (19) (Fig. 1). Furthermore, in ovarian cancer, the tyrosine analog, NK007, can overcome taxol resistance by degrading HK2 (20). In breast cancer, curcumin overcomes resistance to 4-hydroxytamoxifen by inhibiting snail family transcriptional repressor 2 (SLUG or SNAI 2) and subsequently downregulating HK2 expression (21). In a clinical study, the combination of docetaxel and curcumin for the treatment of patients with metastatic castration tolerant prostate cancer resulted in a high response rate, good tolerance and patient acceptability (22) (Table I). In another clinical study, lonidamine (LND), which inhibits aerobic glycolytic activity by influencing HK2 (23), was used with high dose epidoxorubicin for refractory epithelial ovarian cancer. The results indicated that this therapeutic strategy had an excellent second-line therapeutic activity for patients (23). Furthermore, the addition of LND to the carboplatin/cisplatin-paclitaxel standard regimen for advanced ovarian cancer was demonstrated to overcome cisplatin resistance in patients (24).

Phosphoglycerate mutase (PGAM1). PGAM1 facilitates the transformation of 3-phosphoglycerate to 2-phosphoglycerate in glycolysis. Its metabolic activity facilitates cancer metabolism and chemotherapy resistance (25). Previous studies have reported that PGAM1 is upregulated in different types of cancer, such as hepatocellular carcinoma (26), colorectal cancer $(27,28)$ and lung cancer $(29)$. The allosteric regulation of PGAM1 is an important mechanism to change the activity of PGAM1 (25). HKB99, a novel allosteric inhibitor of PGAM1, overcomes erlotinib resistance in non-small cell lung cancer (NSCLC) by enhancing oxidative stress and altering several signaling pathways, including JNK/c-jun activation, and AKT and ERK inhibition (25) (Fig. 1). However, Chen et al (30) discovered that the protein and mRNA expression levels of PGAM1 are downregulated in methotrexate-resistant cells. This phenomenon indicated that aberrant expression of PGAM1 may be associated with multidrug resistance (MDR) in breast cancer. Further studies are required to determine the molecular mechanism underlying drug resistance caused by PGAM1. In addition, few clinical studies have emphasized on exploiting the effect of PGAM1 inhibitors on tumor resistance.

Pyruvate kinase (PKM2). As a gatekeeper of pyruvate flux (1), PKM2 plays an important role in inducing chemotherapy resistance in different types of cancer. In prostate cancer, it has been demonstrated that PKM2 expression is upregulated in enzalutamide-resistant cells (31). Enhancer of zeste 2 polycomb repressive complex 2 subunit inhibitors or lysine 


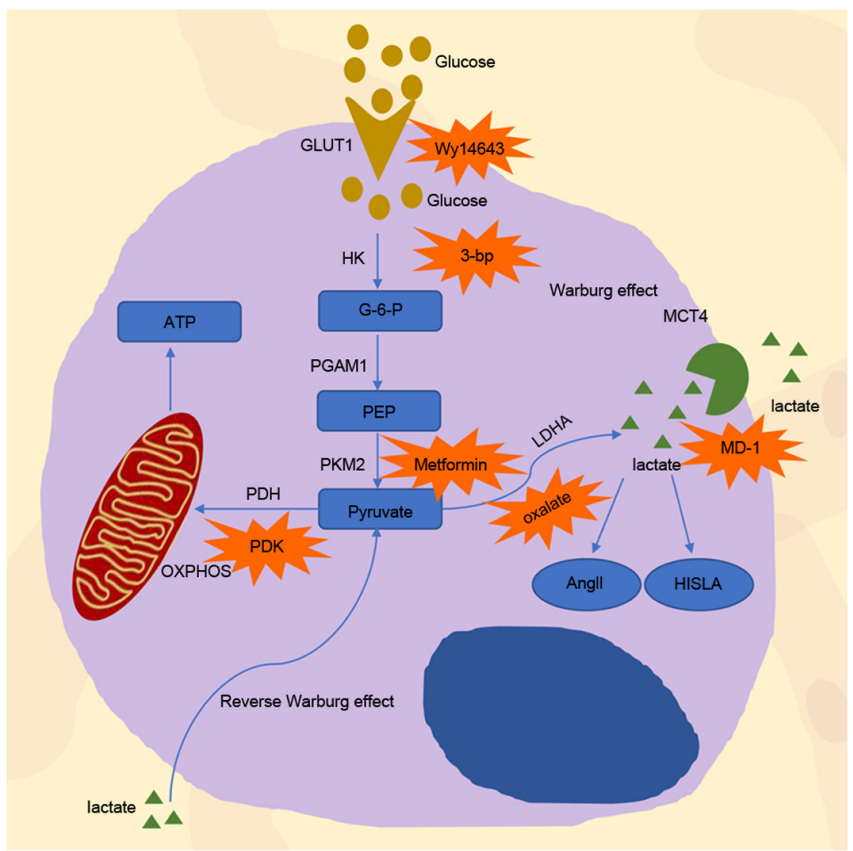

Figure 1. Process of glycolysis inside and outside the cell. G-6-P, glucose-6-phosphate; PEP, phosphoenol pyruvate; HK, hexokinase; PGAM phosphoglycerate mutase; PKM2, pyruvate kinase; PDH, pyruvate dehydrogenase; LDH, lactate dehydrogenase; MCT4, monocarboxylate transporter 4 OXPHOS, oxidative phosphorylation; 3-bp, 3-bromopyruvate; PDK, pyruvate dehydrogenase kinase; MCT, monocarboxylic transporters; GLUT1, glucose transporters 1; AngII, angiotensin II; HISLA, HIF-1 $\alpha$-stabilizing long non-coding RNA.

demethylase 8 knockdown decrease PKM2 expression and result in prostate cancer cell sensitivity to enzalutamide (31). PKM2 also promotes chemotherapy resistance in $\mathrm{ER}^{+}$breast cancer by enhancing aerobic glycolysis (32). In MCF-7 and T47D cells, upregulation of PKM2 hinders sensitivity to adriamycin amycin by enhancing glycolysis (32). Consistent with this result, 2-deoxy-D-glucose (2-DG), a PKM2 inhibitor, can inhibit glycolysis and restore the sensitivity to adriamycin amycin in MCF-7 and T47D cells (32). In addition, PKM2 is positively associated with chemotherapy resistance in pancreatic cancer (33), osteosarcoma (34), colorectal cancer (35) and gastric cancer (36).

PKM2 can translocate to the nucleus where it serves as a transcription coactivator, and this process can induce chemotherapy resistance (37). Ge et al (37) assessed PKM2 expression from nuclear and cytoplasmic extracts in breast cancer. The results demonstrated that PKM2 protein accumulated in the nucleus instead of the cytoplasm in response to overexpression of nicotinamide phosphoribosyl transferase, and induced resistance against tamoxifen in breast cancer cells. Furthermore, PKM2 translocation to the nucleus also leads to resistance to sorafenib and enzalutamide in liver and prostate cancers, respectively $(31,34)$. Polypyrimidine tract-binding protein (PTBP1) is the primary regulator that affects PKM2 expression, and it can influence drug resistance in tumor cells by regulating PKM2 expression $(35,38)$. In colon cancer, PTBP1 knockdown decreases PKM2 expression, inhibits glycolysis and increases cell sensitivity to vincristine and oxaliplatin (35). In addition, upregulation of PTBP1 expression in pancreatic ductal adenocarcinoma cells induces
PKM alternative splicing, which leads to resistance against gemcitabine (38).

It has been demonstrated that a series of drugs combined with chemotherapy drugs can increase the effectiveness of chemotherapy. Shikonin, an inhibitor of PKM2, combined with cisplatin exhibits a more significant cytotoxic effect by inducing necroptosis and ROS production compared with when either one is used alone (39). In osteosarcoma, treatment combined with metformin leads to the inhibition of glucose uptake, lactate production and ATP production by downregulating PKM2 expression. It can also diminish cisplatin resistance in osteosarcoma cancer stem cells $(36,40)$ (Fig. 1). Metformin increases the antitumor effect of other chemotherapy drugs on osteosarcoma stem cells, such as adriamycin and 5-fluorouracil (36). Furthermore, high expression of the ATP binding cassette subfamily B member 1 (ABCB1) gene in patients with acute lymphoblastic leukemia (ALL) is associated with drug resistance and affects prognosis (41). In a clinical study, metformin combined with chemotherapy was particularly effective in patients with elevated ABCB1 expression (clinicaltrials.gov, NCT03118128) (41). In addition, ROS derived from NADPH oxidase 4 (NOX4) can suppress the P300/CBP-associated factor-dependent acetylation and lysosomal degradation of PKM2, leading to an increase in PKM2 expression and the occurrence of chemotherapy resistance (42).

Pyruvate dehydrogenase (PDH) complex. The PDH complex is composed of three enzymes that serve catalytic functions, named E1, E2 and E3. PDH is an E1 enzyme that can catalyze pyruvate conversion to acetyl coenzyme $\mathrm{A}$ in a rate-limiting reaction (43). Pyruvate dehydrogenase kinase (PDK) and pyruvate dehydrogenase phosphatase mainly regulate $\mathrm{PDH}$ activity (43). PDK can inhibit PDH activity by phosphorylating PDH, whereas pyruvate dehydrogenase phosphatase can activate PDH by reversing the phosphorylation of this protein (43) (Fig. 1).

There are four subtypes of PDKs that participate in glycolysis and exert their effects on chemoresistance in tumor response, including PDK1-4 (43). In ovarian cancer cells, overexpression of PDK1 promotes cisplatin resistance (44). Overexpression of PDK1 increases epidermal growth factor receptor (EGFR) phosphorylation and promotes chemotherapy resistance in ovarian cancer (44). Through the transcriptional regulation of cyclin and CBS domain divalent metal cation transporter 3, PDK2 promotes lung adenocarcinoma cell proliferation and cisplatin resistance (45). Several studies have demonstrated that hypoxia-inducible factor (HIF)- $1 \alpha$ regulates the expression of pyruvate dehydrogenase kinase 3 (PDK3) and further induces chemotherapy resistance under hypoxic conditions $(43,46)$. Nucleus accumbens-1 mediates the inhibition of mitochondrial function via HIF-1 $\alpha$-mediated PDK3 overexpression, the inhibition of pyruvate dehydrogenase function and the repression of mitochondrial respiration (47). This process can protect cancer cells from apoptosis under hypoxic conditions (47). Upregulation of PDK4 increases resistance to chemotherapy in hepatocytes and colon cancer cells (48). In addition, PDK4 expression increases in tamoxifen-resistant MCF-7 cells, resulting in 
augmented PDH activity and resistance to tamoxifen mediated by the phosphorylation of PDH (49).

Dichloroacetate (DCA) is a small molecule that promotes the entry of pyruvate into the mitochondria (50). By decreasing the expression of EGFR, DCA can sensitize MCF7 breast cancer cells to cell death induced by tamoxifen (51). The primary molecular mechanism underlying the antitumor effect of DCA involves the conversion of glycolysis into the oxidative metabolism of glucose, which decreases lactic acid production, promotes the production of cytotoxic reactive oxygen intermediates (52) and stimulates the Krebs cycle, and results in chemoresistance and radiotherapy resistance (53). Currently, several studies have combined DCA with some chemotherapy drugs and achieved remarkable results. For example, DCA plus cetuximab notably promotes tumor regression, whereas the use of either drug alone does not induce tumor regression (54). In addition, DCA combined with erlotinib or gefitinib significantly decreases EGFR activity and decreases resistance against tamoxifen (55). Other antitumor drugs have been developed based on the role of DCA. Mitaplatin, a synthetic drug based on cisplatin and DCA, not only destroys nuclear DNA through the action of cisplatin but also attacks mitochondria based on DCA in cancer cells. Under the influence of mitaplatin, the mitochondrial membrane gradient potential is altered in cancer cells, resulting in the release of cytochrome c, translocation of apoptosis-inducing factors from the mitochondria to the nucleus, and apoptosis (56). Due to these properties, mitaplatin can selectively kill tumor cells that are cultured with normal fibroblasts and partially overcome the resistance to cisplatin (56). 2,2-Dichloro-1-(4-isopropoxy-3-nitrophenyl) ethan-1-one(Cpd64) is a novel PDK1 inhibitor that is more efficient and specific than DCA and enhances the anticancer effect of EGFR-TKi (57). In a phase III clinical trial, devimistat (CPI-613), a PDH inhibitor, was combined with large doses of cytarabine and mitoxantrone to treat refractory acute myeloid leukemia and this combination achieved more favorable results (clinicaltrials.gov, NCT03504410) (58).

Lactate dehydrogenase ( $L D H)$. LDH controls the conversion and production of pyruvate and lactic acid (59). Previous studies have demonstrated that LDH is upregulated in several drug-resistant cells (60). Elevated LDH levels can mediate prostate cancer cell resistance to docetaxel (61), colorectal cancer cell resistance to cetuximab (62), oral cancer and breast cancer cell resistance to paclitaxel $(60,63)$, and cartilage sarcoma cell resistance to doxorubicin (DOX) (64).

Several factors can change the expression of LDHA and therefore affect drug resistance. When cancer cells are in an anoxic environment, LDH plays a considerable part in anaerobic metabolism, which is inseparable from HIF-1 $\alpha$ (65). It has been reported that LDH-5, an isozyme of LDH-1, can be induced by hypoxia, and the transcription of LDH-5 is directly regulated by HIF1 (65). Through the upregulation of LDHA, HIF-1 $\alpha$-overexpressing mutants (HIF-1 $\alpha / \Delta \mathrm{ODD})$ are resistant to $G_{1}$ phase cell cycle arrest induced by cetuximab, and acquire cetuximab resistance in head and neck squamous cell carcinoma cell (66). ATP-binding cassette, subfamily C, member 3 (ABCC3), a member of the ATP-binding cassette (ABC) transporter family, is another factor that can alter LDHA levels (67). In human urinary bladder cancer (UBC) cells that lack ABCC3, the blockade of LDHA signaling increases the sensitivity of UBC cells to cis-diamminedichloroplatinum (67).

Due to the critical role of LDHA in drug resistance, a combination of the LDHA inhibitor oxalate and paclitaxel can provide a synergistic inhibitory effect and clinical benefit against paclitaxel-resistant breast cancer due to the enhancement of apoptosis (60) (Fig. 1). Recently, galloflavin was identified as a novel LDH inhibitor that induces human breast cancer cell death by blocking different glycolytic pathways (68).

\section{Glycolysis related substrates and products play roles in chemotherapy resistance}

Glucose and glucose transporters (GLUTS). Changes in glucose can significantly affect the rate of glycolysis, leading to the occurrence of multiple drug resistance (69). Several studies have demonstrated that high glucose intake can induce cisplatin resistance in ovarian and bladder cancer cells, DOX resistance in breast cancer cells, and gemcitabine resistance in pancreatic cancer cells $(18,70,71)$.

In terms of the molecular mechanism, when glucose is severely deficient, glucose regulated protein 78 (GRP78) expression is induced, leading to etoposide resistance and cisplatin susceptibility $(71,72)$. GRP78 and B-cell lymphoma 2 (Bcl-2) competitively associate with Bcl-2 interacting killer (BIK), and upregulated GRP78 expression decreased the association between BIK and Bcl-2, subsequently inhibiting apoptosis and promoting drug resistance in breast cancer cells (73). Lee et al (72) performed a retrospective study and demonstrated a significant association between GRP78 and recurrence time in patients, suggesting that GRP78, which can predict chemotherapy outcomes, deserves further investigation. In a high glucose microenvironment, glucose promotes growth factor receptor signaling through the acetylation of acetyl-CoA-dependent Rictor, which activates rapamycin complex 2 to facilitate resistance to EGFR-, PI3Kor AKT-targeted therapy in glioblastoma (74). Furthermore, 2-DG combined with 5-fluorouracil can significantly improve its therapeutic effect in a high glucose microenvironment (75). $18 \mathrm{~F}$-fluorodeoxyglucose positron emission tomography (18F-FDG PET) is a metabolic imaging tool used to detect lesions with increased glycolysis based on the glucose analog, fluorine-18 fluorodeoxyglucose (76). 18F-FDG PET can predict overall tumor behavior and sensitivity to treatment. In a clinical study, researchers successfully predicted the sensitivity to preoperative chemotherapy in patients with gastroesophageal cancer (77). Another clinical study demonstrated that $18 \mathrm{~F}-\mathrm{FDG}$ PET can predict treatment outcomes for 103/108 (95\%) patients following two courses of conventional standard-dose chemotherapy for advanced Hodgkin's disease (78).

Glucose transports GLUTs primarily regulate glucose flux (79). Glucose transporters are mainly required for glucose uptake in cancer cells to promote cancer cell survival and resistance under hypoxic conditions. Currently, 14 GLUTs have been identified, which exhibit different substrate specificities and tissue expression patterns. Among these, GLUT1 is the most widely expressed transporter, and glucose 
enters cells via glucose transporters to regulate the rate of glycolysis. Thus, GLUT1 dysfunction is associated with resistance (80). In different types of cancer, upregulation of GLUT1 is associated with poor prognosis (81). In NSCLC, activation of GLUT1-mediated glucose metabolism can cause cells to acquire gefitinib and erlotinib resistance (82). Furthermore, in colorectal cancer cells, overexpression of GLUT1 causes chemoresistance (83). In glioma cells, GLUT1 overexpression in paclitaxel-resistant cells restores glucose metabolism, resulting in paclitaxel resistance (84). In addition, in arginine deiminase-resistant cells, GLUT1 expression is increased, consistent with an increase in glycolytic pathway activation (85).

GLUT1 affects tumor cell resistance though several pathways. Activation of the yes-associated protein 1/TEA domain transcription factor 1 pathway may result in increased GLUT1 expression, thereby increasing cell viability in cisplatin-treated cancer cells, decreasing cell death and causing cisplatin resistance (86). The role of GLUT1 in chemotherapy resistance is associated with HIF-1 $\alpha$. Altered expression of GLUT-1 induced by HIF-1 $\alpha$ is associated with augmented proliferation, chemotherapy resistance and metastasis (87). Genistein, a natural isoflavone, can re-sensitize aerobic glycolytic hepatocellular carcinoma cells to apoptosis by downregulating HIF-1 $\alpha$ expression, inactivating GLUT1 and inhibiting aerobic glycolysis, resulting in decreased resistance to sorafenib (87).

Given the important role of GLUT1 in drug resistance, researchers have demonstrated several ways to overcome chemotherapy resistance by inhibiting this protein. In colorectal cancer cells, Wy14,643, a PPAR $\alpha$ agonist, inhibits GLUT1 transcriptional activity, decreases glucose uptake and blocks the mTOR pathway, which in turn decrease tumor growth and chemoresistance (88). GLUT1 can also react with other metabolites to potentiate anti-drug resistance. AG-PEG-SS-PLA, an aminoglucose (AG)-conjugated, redox-responsive nanomicelle from a single disulfide bond-bridged block polymer of polyethylene glycol and polylactic acid, can be formed by GLUT-1 and glutathione polymerization (89). Paclitaxel-loaded AG-PEG-SS-PLA nanomicelles activate the caspase-9 and caspase-3 cascade by upregulating pro-apoptotic proteins, such as $\mathrm{Bcl} 2$ associated $\mathrm{X}$ and $\mathrm{BH} 3$ interacting domain death agonist, and inhibiting Bcl-2, leading to apoptosis and improvement in MDR (89).

Lactate and acidic microenvironment. The Warburg effect implies that the main mechanism of glucose metabolism in cancer cells is aerobic glycolysis, whereas mitochondrial OXPHOS is inhibited, which enhances lactic acid production and consequently promotes the occurrence of drug resistance (60,90-92). Apicella et al (12) demonstrated that MET- or EGFR-addicted cancer cells exhibit increased glycolysis and lactic acid production following long-term utilization of tyrosine kinase inhibitors (TKIs). In cancer cells, lactic acid can promote the production of hepatocyte growth factor (HGF), in a nuclear factor $\mathrm{kb}$-dependent manner. Overexpression of HGF upregulates MET expression by promoting signal transduction, which results in continuous resistance to TKIs. Decreased lactate production attenuates TKI resistance by inducing alterations to HGF and MET activity. In cervical cancer, chemotherapy resistance may be associated with the presence of L- and D-lactic acid in the cervix (93).

When the production of lactic acid increases, the acidic microenvironment changes. Cancer cells express several families of plasma membrane $\mathrm{pH}$ regulators to protect them and maintain normal physiological activities; these families are co-expressed and redundant on the plasma membrane, including carbonic anhydrase IX (CAIX), sodium-hydrogen antiporter 1 (NHE1) and the monocarboxylic transporters (MCT), particularly MCT1 and MCT4. These families can cause acidic by-products to be leaked from the cytoplasm, resulting in the dysregulation of $\mathrm{pH}$ in the tumor microenvironment, that is, alkalized intracellular fluid and acidified extracellular fluid (94). It has been reported that this form of metabolism can enhance resistance to radiation and chemotherapy (94-102).

The monocarboxylic transporters, MCT1 and MCT4, are mainly involved in the transport of lactic acid (Fig. 1). MCT1 is the most common monocarboxylic transporter expressed in p53-deficient tumors (103), whereas MCT4 expression is upregulated under hypoxic conditions and elevates with HIF induction (104). MCT1 is responsible for lactic acid uptake via oxidative cells, and MCT4 is responsible for the release of lactic acid from hypoxic cells (105). Abnormal expression of the MCT family is associated with drug resistance. Apicella et al (12) demonstrated that intratumoral lactic acid increases caused by high MCT1 expression are associated with poor prognosis. In addition, MCT1 is a major transporter that assists 3-bromopyruvate (3-BrPA) (106). Overexpression of MCT1 in cancer cells can sensitize tumor xenografts in response to 3-BrPA treatment in vivo (106). Conversely, downregulation of MCT4 can overcome anti-angiogenic therapy resistance (107). Based on the effects of MCT1 and MCT4, it is reasonable that the monocarboxylate transporter MCT1 and MCT4 dual inhibitor MD-1 can significantly inhibit oral squamous cell carcinoma, an invasive and therapeutic-resistant malignancy (108) (Fig. 1).

Carbonic anhydrase IX (CAIX or CA9) is a tumor-related metalloenzyme that can convert $\mathrm{H}_{2} \mathrm{O}$ and $\mathrm{CO}_{2}$ to $\mathrm{HCO}_{3}{ }^{-}$and $\mathrm{H}^{+}$ions reversibly, and is also induced by HIF (109). It has been reported that transient and long-term exposure to an extracellular acidic microenvironment $(\mathrm{pH}$ 6.7 \pm 0.1$)$ increases CAIX expression in melanoma, breast cancer and colorectal cancer cells (109). Extracellular acidosis can cause chemotherapy resistance, which indicates that there may be an association between CAIX and chemotherapy resistance $(110,111)$. Based on carbonic anhydrase CAIX staining in 188 microarray tumors, it was demonstrated that this protein is upregulated in basal cell-like breast tumors and is associated with chemotherapy resistance (110). Simultaneously, overexpression of CAIX in tongue cancer cells can promote chemotherapy resistance (111). SLC-0111, which inhibits CAIX, enhances the toxic effect of temozolomide and dacarbazine, and is currently being used for the treatment of advanced melanoma. SLC-0111 also increases the response of breast cancer cells to DOX and enhances the inhibitory effects of 5-fluorouracil on colon cancer (109).

NHE-1 is a plasma membrane glycoprotein composed of 815 amino acids, and it is a member of the elevated $\mathrm{Na} / \mathrm{H}$ exchanger gene family, and is also known as a $\mathrm{PH}$ regulator. 
Abnormal NHE-1 expression has been associated with drug resistance $(112,113)$. For example, increased NHE1 expression can promote T cell-ALL resistance to DOX (113). In addition, cariporide, a NHE1 inhibitor, significantly increases breast cancer cell sensitivity to adriamycin by inducing apoptosis, promoting intracellular DOX accumulation and blocking the $\mathrm{G}_{0} / \mathrm{G}_{1}$ phase (114). Recently, cariporide, zoniporide and eniporide, which are effective and selective NHE-1 inhibitors, were demonstrated to be well tolerated in humans. However, only a few clinical trials have been performed in the field of oncology (115).

Due to the high rate of glycolysis, glucose levels within the tumor are deficient, and additional energy is in demand for normal physiological cancer cell activity (116); thus, other sources of energy are required. Excess pyruvate and lactate produced by glycolysis in cancer-associated fibroblasts can be delivered to adjacent cancer cells to enhance the mitochondrial activity, resulting in cancer cell resistance to many clinically used drugs, such as tamoxifen, used in endocrine therapy, Herceptin, used in Her-2-targeted therapy, and ebithromycin, used in chemotherapy (117). In breast cancer cells, this process can assist cancer cell survival in the presence of a lack of glucose for a long time, leading to PI3K/mTOR inhibitor resistance (116).

\section{Glycolysis is associated with immunotherapy resistance}

Recently, immunotherapy has been considered a milestone for cancer therapy. Programmed cell death 1 (PD1), PD1 ligand 1 (PD-L1), and checkpoint molecules, such as cytotoxic $\mathrm{T}$ lymphocyte antigen 4 , have been identified, and drugs targeting them have been used on patients (118). Cancer immunotherapy has achieved significant breakthroughs and success. However, drug resistance has deterred clinical progression for several years. With a deeper understanding of immune mechanisms and immunotherapy efficacy, previous studies have acknowledged that tumors are resistant to immunotherapy via interferon (IFN) signaling and antigen presentation, the PI3K-AKT-mTOR axis, Wnt- $\beta$-catenin signaling, and deletion of the tumor suppressor phosphoinositide phosphatase, PTEN, which can activate different pathways (118-121).

Interferon binds IRF1 and the PD-L1 promoter via the Janus kinase 1 (JAK1)/JAK2-signal transducer and activators of transcription 1 (STAT1)/STAT2/STAT3-interferon regulatory factor 1 (IRF1) axis, thereby regulating the expression of PD-L1 and causing resistance to immune checkpoint inhibitors (119). The loss of copies of IFN- $\gamma$-mediated genes, such as IFNGR1, IRF-1, JAK2 and IFNGR2 can cause metastatic melanoma resistance to ipilimumab (anti-CTLA-4 therapy) (122). The loss of $J A K 1$ and $J A K 2$, IFN- $\gamma$ pathway genes, is associated with resistance to PD-1 therapy (122). Notably, the IFN signaling pathway can also alter glycolysis to cause chemotherapy resistance. Sustained STAT1 signaling causes chemotherapy resistance by increasing the expression of genes associated with glycolysis and OXPHOS (123) (Table II). STAT3 induces chemotherapy resistance by protecting mitochondrial oxidative phosphorylation and controlling the opening of mitochondrial permeability transition pores (124). In addition, IFN- $\gamma$ signaling is downregulated in highly glycolytic tumor cells, and the disruption of tumor IFN- $\gamma$ signaling

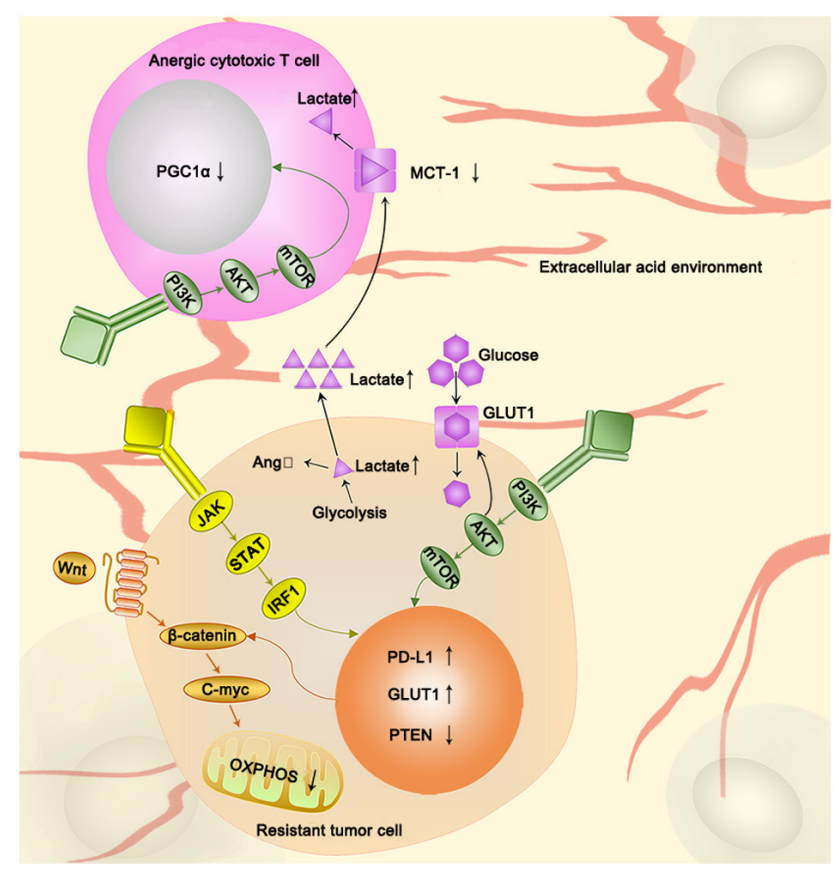

Figure 2. Glycolysis in tumor and tumor microenvironment is associated with immunotherapy resistance. STAT1 mediates tumor resistance to immunotherapy in the tumor microenvironment. Interferon regulates PD-L1 expression via the JAK1/JAK2-STAT1/STAT2/STAT3-IRF1 axis in tumor cells. STAT1 increases the expression of genes associated with glycolysis and oxidative phosphorylation. Wnt ligand inhibits mitochondrial function via the Wnt- $\beta$-catenin target gene, c-myc. However, PTEN loss can induce abnormal accumulation of $\beta$-catenin, and subsequently activate the Wnt- $\beta$-catenin signaling pathway. AKT also plays key roles in regulating immunotherapy resistance by decreasing PGC1 $\alpha$ expression in tumor infiltrating lymphocytes and upregulating membrane localization of GLUT1. During the lactate producing process, PTEN-loss acts as an activator in tumor cells, and increased lactate induces an extracellular acid environment that inhibits MCT-1, which disturbs the metabolism in T-cells. STAT, signal transducer and activators of transcription; PD-L1, programmed cell death-ligand 1; PGC1 $\alpha$, peroxisome proliferator-activated receptor gamma coactivator 1- $\alpha$; GLUT, glucose and glucose transporters; MCT, monocarboxylic transporters; OXPHOS, oxidative phosphorylation; IRF1, interferon regulatory factor 1 .

is an essential cause of tumor immunotherapy resistance (125). In clinical studies, the chimeric anti-CD20 antibody rituximab and IFN-alpha 2 a combined immunotherapy has been proven effective $(126,127)$. In another clinical study, the combination of interleukin- 2 and $\alpha$-IFN, based on a dose-increasing experiment, resulted in an increased response rate (128). These results indicate that the IFN signaling pathway is a good potential target for combination therapy (Fig. 2).

The metabolic reprogramming of tumor cells consumes a lot of energy and nutrients, which means that immune cells are in a state of nutrient depletion. The immune response to the tumor also has a significant negative effect (129). There is considerable evidence that the Wnt- $\beta$-catenin signaling pathway connects glycolysis to the immune response to the tumor. First, Wnt- $\beta$-catenin signaling is closely associated with glycolysis (130). The Wnt- $\beta$-catenin target gene, c-Myc, regulates and controls cancer cell metabolism (130). Wnt5B, a Wnt ligand, has been demonstrated to inhibit mitochondrial functions in triple negative breast cancer cells through c-Myc (131). Secondly, Wnt- $\beta$-catenin signaling is also associated with immunity. The Wnt ligand increases the expression 
Table I. Overview of the clinical studies on the efficacy of glycolysis inhibitions in combination with chemotherapeutics.

\begin{tabular}{lllll}
\hline $\begin{array}{l}\text { Glycolysis } \\
\text { inhibition }\end{array}$ & Chemotherapeutics & $\begin{array}{c}\text { Glycolysis } \\
\text { target }\end{array}$ & \multicolumn{1}{c}{ Cancer } & (Refs.) \\
\hline Metformin & Cisplatin & PKM2 & Osteosarcoma & $(36)$ \\
CPI-613 & Cytarabine/Mitoxantrone & PDH & Acute myeloid leukemia & $(58)$ \\
Lonidamine & Epidoxorubicin & HK2 & Refractory epithelial ovarian cancer & $(23)$ \\
& Cisplatin & HK2 & Ovarian cancer & $(24)$ \\
Curcumin & Docetaxel & HK2 & Prostate cancer/Breast cancer & $(22)$ \\
\hline
\end{tabular}

PKM2, pyruvate kinase; PDH, pyruvate dehydrogenase; HK, hexokinase.

of $\beta$-catenin in dendritic cells, and subsequently, the functions of Tregs and $\mathrm{CD}^{+} \mathrm{T}$ cells are activated, and antitumor immunity is suppressed (120). Thus, targeting the Wnt- $\beta$-catenin signaling pathway has become a strategy that can both target glycolysis and decrease immune resistance. Upon Wnt inhibition, the Wnt- $\beta$-catenin-target gene, MCT1, is also downregulated, leading to a reduction in tumor microenvironment acidity, maintaining antitumor immunity, and preventing cell migration and metastasis (132). Accordingly, there is evidence that a combination of PD-1 and Wnt inhibitors can increase PD-1 inhibitor efficacy (133) (Fig. 2).

Overactivation of the pathological PI3K-AKT-mTOR pathway is the primary mechanism underlying immune checkpoint inhibitor resistance (134). AKT plays a vital role in the tumor microenvironment, whereby it decreases the expression of peroxisome proliferator-activated receptor gamma coactivator $1-\alpha(\mathrm{PGC1} \alpha)$ in tumor-infiltrating lymphocytes (TILs) within the tumor microenvironment. PGC1 $\alpha$ can also regulate the biological function of mitochondria. Thus, a lack of this protein can cause TIL energy exhaustion and decrease antitumor immunity in the tumor microenvironment (135). Based on in vitro experiments, the addition of PGC1 inhibits tumor growth and increases overall survival (135) (Fig. 2).

AKT can promote glucose uptake by increasing the membrane localization of facilitative GLUT1 and GLUT4. AKT also contributes to the phosphorylation of HK-2 and stimulates its translocation to the mitochondria (135). All of these changes can affect glycolysis and induce chemotherapy resistance (135). Accordingly, PI3K-AKT inhibitors have become a focus of research because of their dual anti-chemotherapy and immunotherapy resistance effects (136). In phase I clinical studies, the AKT inhibitor afuresertib combined with carboplatin and paclitaxel exhibited promising results for the treatment of recurrent platinum-resistant ovarian cancer (137). However, clinical trials of AKT inhibitors for the immunotherapy-resistant disease remain to be performed (Fig. 2).

Glycolysis is also associated with immunotherapy resistance through PTEN-deficiency. The abnormal accumulation of $\beta$-catenin, caused by tumor-specific mutations, such as the specific loss of PTEN from melanocytes in lung cancer, leads to activation of the Wnt- $\beta$-catenin signaling pathway (138) (Fig. 2). PTEN-deficiency-associated and activated pathways can cause immune resistance. PTEN deficiency facilitates the immune escape of melanoma by restricting $\mathrm{T}$ cell access to tumor cells and preventing $\mathrm{T}$ cells from killing cancer cells (121). PI3K $\beta$ inhibitors can effectively reverse the immunotherapy resistance caused by the loss of PTEN (121). In PTEN-deficient melanoma cells, some substrates upregulation of glycolysis, such as pyruvate and lactate, provoke overactivation, which is characterized by adoptive $\mathrm{T}$ cell therapy resistance (125). A clinical study has demonstrated that in PTEN-deficient tumors, following treatment of metastatic castration-resistant prostate cancer with the Akt inhibitor ipatasertib coupled with the CYP17 inhibitor abiraterone, radiographic progression-free survival was extended compared with tumors without PTEN deficiency (139). This study further demonstrated that AKT inhibitors combined with antitumor drugs can play an important role in treating PTEN-deficient tumors.

Lactic acid levels are also associated with immune resistance. Lactic acid can be derived from tumor-associated glycolysis and from activated immune cells and macrophages (140). Lactate release in tumor cells also increases the expression of a myeloid-specific lncRNA, HIF-1 $\alpha$-stabilizing long non-coding RNA (HISLA) in macrophages, and elevated HISLA expression promotes aerobic glycolysis in tumor-associated macrophages through extracellular vesicles (EV) transport, which forms a pre-feedback loop (141) (Fig. 1). Blocking EV-mediated HISLA in vivo has been demonstrated to inhibit glycolysis and drug resistance in breast cancer (141). Furthermore, the excessive accumulation of lactic acid can cause immunosuppression, leading to resistance to immunotherapy. First, hypoxic tumor cells produce angiotensin II (AngII) through an anoxia-lactic acid-chymase-dependent mechanism (142). In the tumor microenvironment, local AngII is associated with cancer cell evasion of immune surveillance (143). In addition, the inhibition of AngII signaling may enhance tumor sensitivity to checkpoint immunotherapy (143) (Fig. 2). Secondly, lactic acid can impair the cytotoxic function of $\mathrm{T}$ cells. The activation of $\mathrm{T}$ cells uses glycolysis and relies on lactic acid secretion. The accumulation of intracellular lactic acid in the tumor cell causes an extracellular acidic environment, leading to the inhibition of MCT-1 (144). T cells cannot effectively secret lactate, and under these conditions, their metabolism is disordered, contributing to a significant reduction in cytotoxic activity, which severely affects $\mathrm{T}$ cell functionality (144) (Fig. 2). In addition, lactic acid can increase L-arginine-metabolizing enzyme arginase-1 (ARG1) expression in macrophages and inhibit the antitumor immune response (145). Following treatment with DCA, the declined $A R G 1$ mRNA expression can effectively reactivate the 
Table II. Association between glycolysis and immune drug resistance.

\begin{tabular}{|c|c|c|c|c|}
\hline $\begin{array}{l}\text { Immunotherapy } \\
\text { resistance target }\end{array}$ & $\begin{array}{l}\text { Glycolysis } \\
\text { target }\end{array}$ & Cancer & Correlation & (Refs.) \\
\hline \multirow[t]{4}{*}{ IFN/STAT1 } & ENO1 & Squamous cell carcinoma & STAT1 increases the expression of ENO1 & $(123)$ \\
\hline & LDHA & Squamous cell carcinoma & STAT1 increases the expression of LDHA & $(123)$ \\
\hline & PKM2 & Squamous cell carcinoma & STAT1 increases the expression of PKM2 & $(123)$ \\
\hline & OXPHOS & Mouse embryonal fibroblasts & STAT3 protects OXPHOS & $(124)$ \\
\hline \multirow[t]{2}{*}{ Wnt- $\beta$-catenin } & PDK1 & Colon cancer cells & Blocking $\beta$-catenin decreases PDK1 level & $(130)$ \\
\hline & OXPHOS & TNBC & $\begin{array}{l}\text { Knockdown of WNT5B attenuates } \\
\text { mitochondrial biogenesis and OXPHOS }\end{array}$ & $(131)$ \\
\hline \multirow[t]{2}{*}{$\begin{array}{l}\text { PI3K-AKT-mTOR } \\
\text { pathway }\end{array}$} & GLUT1/4 & Mouse embryonal fibroblasts & $\begin{array}{l}\text { AKT increases the membrane localization } \\
\text { of facilitative GLUT1 and GLUT4 }\end{array}$ & $(135)$ \\
\hline & HK-2 & Mouse embryonal fibroblasts & $\begin{array}{l}\text { AKT contributes to the phosphorylation } \\
\text { of } \mathrm{HK}-2 \text { and stimulates its translocation } \\
\text { to the mitochondria }\end{array}$ & $(135)$ \\
\hline PTEN-deficiency & Pyruvate/lactate & Melanoma & $\begin{array}{l}\text { In PTEN-deficient melanoma cells, } \\
\text { some glycolysis substrates are upregulated, } \\
\text { such as pyruvate and lactate, which is } \\
\text { characterized by adoptive T cell therapy } \\
\text { resistance }\end{array}$ & $(125)$ \\
\hline
\end{tabular}

IFN, interferon; STAT, signal transducer and activators of transcription; LDH, lactate dehydrogenase; PKM2, pyruvate kinase; OXPHOS, oxidative phosphorylation; GLUT1, glucose transporters 1; HK, hexokinase.

immune state regulated by lactic acid and improve antitumor immunotherapy benefits (145).

\section{Transition of glycolysis to OXPHOS enhances drug resistance}

The Warburg effect indicates that tumor cells tend to undergo glycolysis regardless of aerobic and anaerobic conditions, which implies that mitochondrial dysfunction is a feature of tumor cells (146). However, recently, this statement has been challenged (147). Several tumor cells have been reported to have metabolic plasticity, indicating a transformation from glycolysis to mitochondrial OXPHOS, leading to the production of vast amounts of energy and resistance to drugs (148). Recent evidence suggests that cancer cells can obtain glycolysis/OXPHOS mixed phenotypes, in which the ATP production is an outcome from both glycolysis and OXPHOS to support physiological activity of cells (149). In addition, cells with this characteristic are more likely to acquire drug resistance (150). When lactic acid increases, it can be used as an energy source by adjacent cancer cells to activate mitochondria and stimulate OXPHOS (151) (Fig. 1).

Such changes in OXPHOS can affect the drug resistance of tumor cells. Following chemotherapy, Farge et al (150) described a new method to identify and study acute myeloid leukemia (AML) cells remaining in the bone marrow. The results demonstrated that OXPHOS is increased in AML cells remaining in the bone marrow of mice following cytarabine therapy, and that the inhibition of OXPHOS can re-sensitize AML cells to cytarabine. In epithelial ovarian cancer, the oxygen consumption rate, mitochondrial respiration and oxidative phosphorylation in cisplatin-resistant cells were higher than those in cisplatin-sensitive cells (152). The activation of OXPHOS is a typical feature of hepatocellular carcinoma cell resistance to DOX (153). Generally, increased OXPHOS can promote the occurrence of chemotherapy resistance (150).

OXPHOS affects the treatment of tumors in several ways. As it results in the production of a large amount of ATP, this is bound to stimulate the activity of some transporters, one of which is drug transporters. In breast cancer cells, the continuous supply of ATP derived from OXPHOS is utilized by $\mathrm{ABC}$ transporters, leading to the outflow of DOX and the induction of an MDR phenotype (148). Tumor stem cells are also associated with drug resistance caused by OXPHOS. Increased OXPHOS mediated by mitochondria can stimulate tumor stem cells to expand, conferring resistance to tumor cells (154). Furthermore, NANOG, a stem cell marker, inhibits mitochondrial OXPHOS genes and promotes sorafenib resistance (155).

Several drugs inhibit the occurrence and development of tumors, and they can also affect OXPHOS. Some drugs, like cytarabine, 5-fluorouracil, TKIs, MAPKi and BRAFi can promote OXPHOS activity and increase drug resistance in the mitochondria, whereas others, such as anthracyclines, etoposide, sorafenib, paclitaxel and staurosporine, significantly decrease OXPHOS activity in the mitochondria (147). For those drugs that promote OXPHOS activity in mitochondria, it is necessary to find a better way to solve the associated drug resistance. Metformin is a type of mitochondrial inhibitor and combining it with cisplatin can attenuate cisplatin resistance in epithelial ovarian cancer cells (152). Metformin can also 
be combined with TKIs to overcome tumor chemotherapy resistance (147). In addition, targeting mitochondrial respiration and HIF-1 $\alpha$ may reverse tumor cell chemotherapeutic resistance (154). When the anoxic environment is destroyed and the HIF1 $\alpha$ pathway is blocked, sex-determining region $Y$ (SRY)-Box 2 drives OXPHOS reprogramming, which helps tumor cells obtain an invasive oxidative tumor phenotype and enhance drug resistance and metastatic ability (156).

\section{Conclusions}

Changes in glycolysis, particularly increases in key enzymes and intermediates of this pathway, can affect the sensitivity of tumors to chemotherapeutic reagents, resulting in an increase in ATP production, and providing sufficient energy for the biological activity of tumor cells $(14,69)$. This process enhances the repair of DNA damage, increases the phosphorylation, translocation into the nucleus, and autophagy-associated activity of enzymes, and causes drug resistance (157). In addition, several clinical trials have been performed to investigate the therapeutic effect of glycolysis-targeting therapy combined with clinical first-and second-line chemotherapeutic drugs on tumors (Table I).

Recently, several studies have demonstrated that the role of mitochondria in tumor metabolism is becoming essential. The reverse Warburg effect emerged, indicating that the increase in lactic acid as an energy material can be converted into pyruvate in the mitochondria and enhance mitochondrial activity and OXPHOS in adjacent cells (117). In addition, tumor cells also have metabolic plasticity. Glycolysis can be moderately transformed into OXPHOS when the external environment changes or there is plenty of oxygen around the tumor cells. This transformation is closely associated with chemotherapy $(118,148)$. Increased mitochondrial activity and OXPHOS results in the production of higher levels of ATP and NADPH. High levels of ATP provide a vast amount of energy to tumor cells, and NADPH is a key antioxidant that can decrease ROS damage to tumor cells (158).

With an increase in studies on tumor immunity, immune checkpoint inhibitors have been developed for clinical applications (149). However, immunotherapy resistance is remains a major challenge. Based on a broadened understanding of tumor immunity, it is apparent that immunotherapy resistance is closely associated with glucose metabolism (125). The PI3K-AKT-mTOR axis, PTEN deficiency, IFN signaling and the Wnt- $\beta$-catenin signaling pathway can affect corresponding enzymes involved in glycolysis and enhance immunotherapy resistance $(123,125,131,135)$. Conversely, the release of lactic acid, a glycolysis intermediate metabolite, can promote the occurrence of immunotherapy resistance. The interaction between glucose metabolism and immunotherapy resistance forms a positive feedback pathway and constitutes an important factor in tumor drug resistance (141). Currently, there are a few studies on the effect of the PI3K-AKT-mTOR axis, PTEN deficiency, IFN signaling, Wnt- $\beta$-catenin signaling pathway targeting agents on immunotherapy drug resistance, and chemotherapy resistance. The interdisciplinary study on tumor glycolysis and immunotherapy resistance should endeavor to receive more attention to proceed to understand the molecular mechanisms involved.

\section{Future direction and perspectives}

Regarding these glucose metabolic processes, targeted inhibitors may be used in combination with chemotherapy reagents or immune checkpoint inhibitors in the future. However, due to the lack of tumor drug resistance markers, targeted inhibitor prognostic indexes, and the specificity of these inhibitors, their clinical application is profoundly limited. In general, altered glycolysis, as a ubiquitous feature of drug-resistant tumor cells, represents a promising target, and novel strategy to overcome drug resistance clinically.

\section{Acknowledgements}

Not applicable.

\section{Funding}

The present review was supported by grants from the National Natural Science Foundation of China (grant nos. 81672612 and 81572607) and the Project of Invigorating Health Care through Science, Technology and Education (The Project of Jiangsu Provincial Medical Youth Talent; grant no. QNRC2016095).

\section{Availability of data and materials}

Not applicable.

\section{Authors' contributions}

JP and YC designed the present review and drafted the initial manuscript. XW and YH analyzed the data. SX, WZ and SW revised the review for important intellectual content. ZF reviewed and critiqued the review following revisions. HX designed the present review, edited, reviewed and critiqued the manuscript. All authors have read and approved the final manuscript.

\section{Ethics approval and consent to participate}

Not applicable.

\section{Patient consent for publication}

Not applicable.

\section{Competing interests}

The authors declare that they have no competing interests.

\section{References}

1. Zaal EA and Berkers CR: The influence of metabolism on drug response in cancer. Front Oncol 8: 500, 2018.

2. Warburg $\mathrm{O}$, Wind $\mathrm{F}$ and Negelein $\mathrm{E}$ : The metabolism of tumors in the body. J Gen Physiol 8: 519-530, 1927.

3. Bonuccelli G, Whitaker-Menezes D, Castello-Cros R, Pavlides S, Pestell RG,Fatatis A, Witkiewicz AK, Vander Heiden MG,MignecoG, Chiavarina B, et al: The reverse Warburg effect: Glycolysis inhibitors prevent the tumor promoting effects of caveolin-1 deficient cancer associated fibroblasts. Cell Cycle 9: 1960-1971, 2010. 
4. Holohan C, Van Schaeybroeck S, Longley DB and Johnston PG Cancer drug resistance: An evolving paradigm. Nat Rev Cancer 13: 714-726, 2013.

5. Boumahdi S and de Sauvage FJ: The great escape: Tumour cell plasticity in resistance to targeted therapy. Nat Rev Drug Discov 19: 39-56, 2020.

6. Gershon O, Ezenwa NE and Osabohien R: Implications of oil price shocks on net oil-importing African countries. Heliyon 5: e02208, 2019.

7. Woo YM, Shin Y, Lee EJ, Lee S, Jeong SH, Kong HK, Park EY, Kim HK, Han J, Chang M and Park JH: Inhibition of aerobic glycolysis represses Akt/mTOR/HIF- $1 \alpha$ axis and restores tamoxifen sensitivity in antiestrogen-resistant breast cancer cells PLoS One 10: e0132285, 2015.

8. Komurov K, Tseng JT, Muller M, Seviour EG, Moss TJ, Yang L, Nagrath D and Ram PT: The glucose-deprivation network counteracts lapatinib-induced toxicity in resistant ErbB2-positive breast cancer cells. Mol Syst Biol 8: 596, 2012.

9. Ruprecht B, Zaal EA, Zecha J, Wu W, Berkers CR, Kuster B and Lemeer S: Lapatinib resistance in breast cancer cells is accompanied by phosphorylation-mediated reprogramming of glycolysis. Cancer Res 77: 1842-1853, 2017.

10. He M, Jin Q, Chen C, Liu Y, Ye X, Jiang Y, Ji F, Qian H, Gan D, Yue $\mathrm{S}$, et al: The miR-186-3p/EREG axis orchestrates tamoxifen resistance and aerobic glycolysis in breast cancer cells. Oncogene 38: 5551-5565, 2019

11. Icard P, Shulman S, Farhat D, Steyaert JM, Alifano M and Lincet $\mathrm{H}$ : How the Warburg effect supports aggressiveness and drug resistance of cancer cells? Drug Resist Updat 38: 1-11, 2018.

12. Apicella M, Giannoni E, Fiore S, Ferrari KJ, Fernández-Pérez D, Isella C, Granchi C, Minutolo F, Sottile A, Comoglio PM, et al: Increased lactate secretion by cancer cells sustains non-cellautonomous adaptive resistance to MET and EGFR targeted therapies. Cell Metab 28: 848-865 e6, 2018.

13. Varghese E, Samuel SM, Liskova A, Samec M, Kubatka P and Busselberg D: Targeting glucose metabolism to overcome resistance to anticancer chemotherapy in breast cancer. Cancers (Basel) 12: 2252, 2020

14. Liu X, Miao W, Huang M, Li L, Dai X and Wang Y: Elevated hexokinase II expression confers acquired resistance to 4-hydroxytamoxifen in breast cancer cells. Mol Cell Proteomics 18: 2273-2284, 2019

15. Krasnov GS, Dmitriev AA, Lakunina VA, Kirpiy AA and Kudryavtseva AV: Targeting VDAC-bound hexokinase II: A promising approach for concomitant anti-cancer therapy. Expert Opin Ther Targets 17: 1221-1233, 2013.

16. Yang T, Ren C, Qiao P, Han X, Wang L, Lv S, Sun Y, Liu Z, Du Y and Yu Z: Correction: PIM2-mediated phosphorylation of hexokinase 2 is critical for tumor growth and paclitaxel resistance in breast cancer. Oncogene 39: 720-721, 2020.

17. Yang T, Ren C, Qiao P, Han X, Wang L, Lv S, Sun Y, Liu Z, Du Y and Yu Z: PIM2-mediated phosphorylation of hexokinase 2 is critical for tumor growth and paclitaxel resistance in breast cancer. Oncogene 37: 5997-6009, 2018.

18. Fan K, Fan Z, Cheng H, Huang Q, Yang C, Jin K, Luo G, Yu X and Liu C: Hexokinase 2 dimerization and interaction with voltage-dependent anion channel promoted resistance to cell apoptosis induced by gemcitabine in pancreatic cancer. Cancer Med 8: 5903-5915, 2019.

19. Rai Y, Yadav P, Kumari N, Kalra N and Bhatt AN: Hexokinase II inhibition by 3-bromopyruvate sensitizes myeloid leukemic cells K-562 to anti-leukemic drug, daunorubicin. Biosci Rep 39 BSR20190880, 2019.

20. Li Z, Tang X, Luo Y, Chen B, Zhou C, Wu X, Tang Z, Qi X, Cao G, Hao J, et al: NK007 helps in mitigating paclitaxel resistance through p38MAPK activation and HK2 degradation in ovarian cancer. J Cell Physiol: Feb 20, 2019 (Epub ahead of print).

21. Geng C, Li J, Ding F, Wu G, Yang Q, Sun Y, Zhang Z, Dong T and Tian X: Curcumin suppresses 4-hydroxytamoxifen resistance in breast cancer cells by targeting SLUG/Hexokinase 2 pathway. Biochem Biophys Res Commun 473: 147-153, 2016.

22. Mahammedi H,Planchat E, Pouget M, Durando X, Curé H, Guy L, Van-Praagh I, Savareux L, Atger M, Bayet-Robert M, et al: The new combination docetaxel, prednisone and curcumin in patients with castration-resistant prostate cancer: A pilot phase II study. Oncology 90: 69-78, 2016.

23. Gadducci A, Brunetti I, Muttini MP, Fanucchi A, Dargenio F, Giannessi PG and Conte PF: Epidoxorubicin and lonidamine in refractory or recurrent epithelial ovarian cancer. Eur J Cancer 30A: 1432-1435, 1994.
24. De Lena M, Lorusso V, Latorre A, Fanizza G, Gargano G, Caporusso L, Guida M, Catino A, Crucitta E, Sambiasi D and Mazzei A: Paclitaxel, cisplatin and lonidamine in advanced ovarian cancer. A phase II study. Eur J Cancer 37: 364-368, 2001.

25. Huang K, Liang Q, Zhou Y, Jiang LL, Gu WM, Luo MY, Tang YB, Wang Y, Lu W, Huang M, et al: A novel allosteric inhibitor of phosphoglycerate mutase 1 suppresses growth and metastasis of non-small-cell lung cancer. Cell Metab 30: 1107-1119.e8, 2019.

26. Ren F, Wu H, Lei Y, Zhang H, Liu R, Zhao Y, Chen X, Zeng D, Tong A, Chen L, et al: Quantitative proteomics identification of phosphoglycerate mutase 1 as a novel therapeutic target in hepatocellular carcinoma. Mol Cancer 9: 81, 2010.

27. Usuba T, Ishibashi Y, Okawa Y, Hirakawa T, Takada K and Ohkawa K: Purification and identification of monoubiquitin-phosphoglycerate mutase B complex from human colorectal cancer tissues. Int J Cancer 94: 662-668, 2001.

28. Liu L, Wang S, Zhang Q and Ding Y: Identification of potential genes/proteins regulated by Tiam1 in colorectal cancer by microarray analysis and proteome analysis. Cell Biol Int 32: $1215-1222,2008$.

29. Chen G, Gharib TG, Wang H, Huang CC, Kuick R, Thomas DG, Shedden KA, Misek DE, Taylor JM, Giordano TJ, et al: Protein profiles associated with survival in lung adenocarcinoma. Proc Natl Acad Sci USA 100: 13537-13542, 2003.

30. Chen SY, Cai JX, Zhang WP, Zhang XW, Hu SS, Lu J, Xing JF and Dong YL: Proteomic identification of differentially expressed proteins associated with the multiple drug resistance in methotrexateresistant human breast cancer cells. Int J Oncol 45: 448-458, 2014

31. Wang HJ, Pochampalli M, Wang LY, Zou JX, Li PS, Hsu SC, Wang BJ, Huang SH, Yang P, Yang JC, et al: KDM8/JMJD5 as a dual coactivator of $A R$ and $P K M 2$ integrates $A R / E Z H 2$ network and tumor metabolism in CRPC. Oncogene 38: 17-32, 2019.

32. Qian Y, Bi L, Yang Y and Wang D: Effect of pyruvate kinase M2-regulating aerobic glycolysis on chemotherapy resistance of estrogen receptor-positive breast cancer. Anticancer Drugs 29: 616-627, 2018.

33. Tian S, Li P, Sheng S and Jin X: Upregulation of pyruvate kinase M2 expression by fatty acid synthase contributes to gemcitabine resistance in pancreatic cancer. Oncol Lett 15: 2211-2217, 2018.

34. Wong TL, Ng KY, Tan KV, Chan LH, Zhou L, Che N, Hoo RLC, Lee TK, Richard S, Lo CM, et al: CRAF methylation by PRMT6 regulates aerobic glycolysis driven hepatocarcinogenesis via ERK-dependent PKM2 nuclear relocalization and activation. Hepatology 71: 1279-1296, 2020.

35. Cheng C, Xie Z, Li Y, Wang J, Qin C and Zhang Y: PTBP1 knockdown overcomes the resistance to vincristine and oxaliplatin in drug-resistant colon cancer cells through regulation of glycolysis. Biomed Pharmacother 108: 194-200, 2018.

36. Shang D, Wu J, Guo L, Xu Y, Liu L and Lu J: Metformin increases sensitivity of osteosarcoma stem cells to cisplatin by inhibiting expression of PKM2. Int J Oncol 50: 1848-1856, 2017.

37. Ge X, Zhao Y, Dong L, Seng J, Zhang X and Dou D: NAMPT regulates PKM2 nuclear location through 14-3-3 $\xi$ : Conferring resistance to tamoxifen in breast cancer. J Cell Physiol 234: 23409-23420, 2019.

38. Calabretta S, Bielli P, Passacantilli I, Pilozzi E, Fendrich V, Capurso G, Fave GD and Sette C: Modulation of PKM alternative splicing by PTBP1 promotes gemcitabine resistance in pancreatic cancer cells. Oncogene 35: 2031-2039, 2016.

39. Wang X, Zhang F and Wu XR: Inhibition of pyruvate kinase M2 markedly reduces chemoresistance of advanced bladder cancer to cisplatin. Sci Rep 7: 45983, 2017.

40. Gatti M, Solari A, Pattarozzi A, Campanella C, Thellung S, Maniscalco L, De Maria R, Würth R, Corsaro A, Bajetto A, et al: In vitro and in vivo characterization of stem-like cells from canine osteosarcoma and assessment of drug sensitivity. Exp Cell Res 363: 48-64, 2018.

41. Ramos-Penafiel C, Olarte-Carrillo I, Ceron-Maldonado R, Rozen-Fuller E, Kassack-Ipiña JJ, Meléndez-Mier G, Collazo-Jaloma J and Martínez-Tovar A: Effect of metformin on the survival of patients with ALL who express high levels of the ABCB1 drug resistance gene. J Transl Med 16: 245, 2018.

42. Shanmugasundaram K, Nayak BK, Friedrichs WE, Kaushik D, Rodriguez R and Block K: NOX4 functions as a mitochondrial energetic sensor coupling cancer metabolic reprogramming to drug resistance. Nat Commun 8: 997, 2017.

43. Lu CW, Lin SC, Chen KF, Lai YY and Tsai SJ: Induction of pyruvate dehydrogenase kinase-3 by hypoxia-inducible factor-1 promotes metabolic switch and drug resistance. J Biol Chem 283: 28106-28114, 2008. 
44. Zhang M, Cong Q, Zhang XY, Zhang MX, Lu YY and Xu CJ: Pyruvate dehydrogenase kinase 1 contributes to cisplatin resistance of ovarian cancer through EGFR activation. J Cell Physiol 234: 6361-6370, 2019.

45. Hu T, Yu S, Li Y, Ren H, Ning Q, Wang J, Liang X and Li M: PDK2 induces cisplatin-resistance in lung adenocarcinoma via transcriptional regulation of CNNM3. J Drug Target 27: 460-465, 2019

46. Lu CW, Lin SC, Chien CW, Lin SC, Lee CT, Lin BW, Lee JC and Tsai SJ: Overexpression of pyruvate dehydrogenase kinase 3 increases drug resistance and early recurrence in colon cancer. Am J Pathol 179: 1405-1414, 2011

47. Ren YJ, Wang XH, Ji C, Guan YD, Lu XJ, Liu XR, Zhang HH, Guo LC, Xu QH, Zhu WD, et al: Silencing of NAC1 expression induces cancer cells oxidative stress in hypoxia and potentiates the therapeutic activity of elesclomol. Front Pharmacol 8: 804 2017.

48. Strowitzki MJ,RadhakrishnanP,Pavicevic S, Scheer J,KimmerG, Ritter AS, Tuffs C, Volz C, Vondran F, Harnoss JM, et al: High hepatic expression of PDK4 improves survival upon multimodal treatment of colorectal liver metastases. Br J Cancer 120 675-688, 2019.

49. Walter W, Thomalla J, Bruhn J, Fagan DH, Zehowski C, Yee D and Skildum A: Altered regulation of PDK4 expression promotes antiestrogen resistance in human breast cancer cells. Springerplus 4: 689, 2015.

50. Michelakis ED, Webster L and Mackey JR: Dichloroacetate (DCA) as a potential metabolic-targeting therapy for cancer. Br J Cancer 99: 989-994, 2008.

51. Woo SH, Seo SK, Park Y, Kim EK, Seong MK, Kim HA, Song JY, Hwang SG, Lee JK, Noh WC and Park IC: Dichloroacetate potentiates tamoxifen-induced cell death in breast cancer cells via downregulation of the epidermal growth factor receptor. Oncotarget 7: 59809-59819, 2016.

52. Xuan Y, Hur H, Ham IH, Yun J, Lee JY, Shim W, Kim YB, Lee G, Han SU and Cho YK: Dichloroacetate attenuates hypoxia-induced resistance to 5-fluorouracil in gastric cancer through the regulation of glucose metabolism. Exp Cell Res 321: 219-230, 2014

53. Clayton: Case of ulceration of the larynx. Med Phys J 32: 25-26, 1814.

54. Lu H, Lu Y, Xie Y, Qiu S, Li X and Fan Z: Rational combination with PDK1 inhibition overcomes cetuximab resistance in head and neck squamous cell carcinoma. JCI Insight 4: e131106, 2019.

55. Yang Z and Tam KY: Anti-cancer synergy of dichloroacetate and EGFR tyrosine kinase inhibitors in NSCLC cell lines. Eur J Pharmacol 789: 458-467, 2016

56. Xue X, You S, Zhang Q, Wu Y, Zou GZ, Wang PC, Zhao YL, $\mathrm{Xu}$ Y, Jia L, Zhang X and Liang XJ: Mitaplatin increases sensitivity of tumor cells to cisplatin by inducing mitochondrial dysfunction. Mol Pharm 9: 634-644, 2012.

57. Yang Z, Zhang SL, Hu X and Tam KY: Inhibition of pyruvate dehydrogenase kinase 1 enhances the anti-cancer effect of EGFR tyrosine kinase inhibitors in non-small cell lung cancer. Eur J Pharmacol 838: 41-52, 2018.

58. Pardee TS, Luther S, Buyse M, Powell BL and Cortes $\mathrm{J}$ : Devimistat in combination with high dose cytarabine and mitoxantrone compared with high dose cytarabine and mitoxantrone in older patients with relapsed/refractory acute myeloid leukemia: ARMADA 2000 Phase III study. Future Oncol 15: 3197-3208, 2019.

59. Ding J, Karp JE and Emadi A: Elevated lactate dehydrogenase (LDH) can be a marker of immune suppression in cancer: Interplay between hematologic and solid neoplastic clones and their microenvironments. Cancer Biomark 19: 353-363, 2017.

60. Zhou M, Zhao Y, Ding Y, Liu H, Liu Z, Fodstad O, Riker AI, Kamarajugadda S, Lu J, Owen LB, et al: Warburg effect in chemosensitivity: Targeting lactate dehydrogenase-A re-sensitizes taxol-resistant cancer cells to taxol. Mol Cancer 9: 33, 2010.

61. Muramatsu H, Sumitomo M, Morinaga S, Kajikawa K, Kobayashi I, Nishikawa G, Kato Y, Watanabe M, Zennami K, Kanao K, et al: Targeting lactate dehydrogenase-A promotes docetaxel-induced cytotoxicity predominantly in castration-resistant prostate cancer cells. Oncol Rep 42: 224-230, 2019.

62. Nagamine A, Araki T, Nagano D, Miyazaki M and Yamamoto K L-Lactate dehydrogenase B may be a predictive marker for sensitivity to anti-EGFR monoclonal antibodies in colorectal cancer cell lines. Oncol Lett 17: 4710-4716, 2019.
63. Feng L, E LL, Soloveiv MM, Wang DS, Zhang BO, Dong YW and Liu HC: Synergistic cytotoxicity of cisplatin and Taxol in overcoming Taxol resistance through the inhibition of LDHA in oral squamous cell carcinoma. Oncol Lett 9: 1827-1832, 2015.

64. Hua G, Liu Y, Li X, Xu P and Luo Y: Targeting glucose metabolism in chondrosarcoma cells enhances the sensitivity to doxorubicin through the inhibition of lactate dehydrogenase-A. Oncol Rep 31: 2727-2734, 2014.

65. Koukourakis MI, Giatromanolaki A, Sivridis E, Bougioukas G, Didilis V, Gatter KC and Harris AL: Lactate dehydrogenase-5 (LDH-5) overexpression in non-small-cell lung cancer tissues is linked to tumour hypoxia, angiogenic factor production and poor prognosis. Br J Cancer 89: 877-885, 2003.

66. Lu H, Li X, Luo Z, Liu J and Fan Z: Cetuximab reverses the Warburg effect by inhibiting HIF-1-regulated LDH-A. Mol Cancer Ther 12: 2187-2199, 2013.

67. Liu X, Yao D, Liu C, Cao Y, Yang Q, Sun Z and Liu D: Overexpression of $\mathrm{ABCC} 3$ promotes cell proliferation, drug resistance, and aerobic glycolysis and is associated with poor prognosis in urinary bladder cancer patients. Tumour Biol 37: 8367-8374, 2016.

68. Aggarwal A and Keluskar V: Epithelioid hemangioma (angiolymphoid hyperplasia with eosinophilia) in the oral mucosa. Indian J Dent Res 23: 271-274, 2012.

69. Hamadneh L, Abuarqoub R, Alhusban A and Bahader M: Upregulation of PI3K/AKT/PTEN pathway is correlated with glucose and glutamine metabolic dysfunction during tamoxifen resistance development in MCF-7 cells. Sci Rep 10: 21933, 2020.

70. Sun H, Wang H, Wang X, Aoki Y, Wang X, Yang Y, Cheng X, Wang $\mathrm{Z}$ and Wang $\mathrm{X}$ : Aurora-A/SOX8/FOXK1 signaling axis promotes chemoresistance via suppression of cell senescence and induction of glucose metabolism in ovarian cancer organoids and cells. Theranostics 10: 6928-6945, 2020.

71. Dong D, Ko B, Baumeister P, Swenson S, Costa F, Markland F, Stiles C, Patterson JB, Bates SE and Lee AS: Vascular targeting and antiangiogenesis agents induce drug resistance effector GRP78 within the tumor microenvironment. Cancer Res 65: 5785-5791, 2005

72. Lee E, Nichols P, Spicer D, Groshen S, Yu MC and Lee AS: GRP78 as a novel predictor of responsiveness to chemotherapy in breast cancer. Cancer Res 66: 7849-7853, 2006.

73. Zhou H, Zhang Y, Fu Y, Chan L and Lee AS: Novel mechanism of anti-apoptotic function of $78-\mathrm{kDa}$ glucose-regulated protein (GRP78): Endocrine resistance factor in breast cancer, through release of B-cell lymphoma 2 (BCL-2) from BCL-2-interacting killer (BIK). J Biol Chem 286: 25687-25696, 2011.

74. Cristanziano VD, Bottcher S, Diedrich S, Timmen-Wego M, Knops E, Lübke N, Kaiser R, Pfister H, Kaboré Y and D'Alfonso R: Detection and characterization of enteroviruses and parechoviruses in healthy people living in the South of Cote d'Ivoire. J Clin Virol 71: 40-43, 2015.

75. Cheng Y, Diao D, Zhang H, Guo Q, Wu X, Song Y and Dang C: High glucose-induced resistance to 5-fluorouracil in pancreatic cancer cells alleviated by 2-deoxy-D-glucose. Biomed Rep 2: 188-192, 2014.

76. Panizo C, Perez-Salazar M, Bendandi M, Rodríguez-Calvillo M, Boán JF, García-Velloso MJ, Richter J and Rocha E: Positron emission tomography using $18 \mathrm{~F}-$ fluorodeoxyglucose for the evaluation of residual Hodgkin's disease mediastinal masses. Leuk Lymphoma 45: 1829-1833, 2004.

77. Weber WA, Ott K, Becker K, Dittler HJ, Helmberger H, Avril NE, Meisetschläger G, Busch R, Siewert JR, Schwaiger M and Fink U: Prediction of response to preoperative chemotherapy in adenocarcinomas of the esophagogastric junction by metabolic imaging. J Clin Oncol 19: 3058-3065, 2001.

78. Gallamini A, Rigacci L, Merli F, Nassi L, Bosi A, Capodanno I, Luminari S, Vitolo U, Sancetta R, Iannitto E, et al: The predictive value of positron emission tomography scanning performed after two courses of standard therapy on treatment outcome in advanced stage Hodgkin's disease. Haematologica 91: 475-481, 2006.

79. Chen LQ, Cheung LS, Feng L, Tanner W and Frommer WB: Transport of sugars. Annu Rev Biochem 84: 865-894, 2015

80. Reckzeh ES and Waldmann H: Small-Molecule inhibition of glucose transporters GLUT-1-4. Chembiochem 21: 45-52, 2020.

81. Mayer A, Hockel M, Wree A and Vaupel P: Microregional expression of glucose transporter-1 and oxygenation status: Lack of correlation in locally advanced cervical cancers. Clin Cancer Res 11: 2768-2773, 2005. 
82. Suzuki S, Okada M, Takeda H, Kuramoto K, Sanomachi T, Togashi K, Seino S, Yamamoto M, Yoshioka T and Kitanaka C: Involvement of GLUT1-mediated glucose transport and metabolism in gefitinib resistance of non-small-cell lung cancer cells Oncotarget 9: 32667-32679, 2018.

83. Wang T, Ning K, Sun X, Zhang C, Jin LF and Hua D: Glycolysis is essential for chemoresistance induced by transient receptor potential channel C5 in colorectal cancer. BMC Cancer 18: 207, 2018.

84. Guan DG, Chen HM, Liao SF and Zhao TZ: Combination of temozolomide and Taxol exerts a synergistic inhibitory effect on Taxolresistant glioma cells via inhibition of glucose metabolism. Mol Med Rep 12: 7705-7711, 2015.

85. Liu PJ, Ma F, Lou HP, Zhu YN and Chen Y: Relationship between serum uric acid levels and metabolic syndrome in Chinese postmenopausal women. Climacteric 17: 148-154, 2014.

86. Wang L, Sun J, Gao P, Su K, Wu H, Li J and Lou W: Wnt1-inducible signaling protein 1 regulates laryngeal squamous cell carcinoma glycolysis and chemoresistance via the YAP1/TEAD1/GLUT1 pathway. J Cell Physiol: Feb 25, 2019 (Epub ahead of print).

87. Li S, Li J, Dai W, Zhang Q, Feng J, Wu L, Liu T, Yu Q, Xu S, Wang W, et al: Genistein suppresses aerobic glycolysis and induces hepatocellular carcinoma cell death. Br J Cancer 117: $1518-1528,2017$

88. Gou Q, Dong C, Jin J, Liu Q, Lu W, Shi J and Hou Y: PPARo agonist alleviates tumor growth and chemo-resistance associated with the inhibition of glucose metabolic pathway. Eur J Pharmacol 863: 172664, 2019.

89. Zhou Y, Wen H, Gu L, Fu J, Guo J, Du L, Zhou X, Yu X, Huang Y and Wang H: Aminoglucose-functionalized, redox-responsive polymer nanomicelles for overcoming chemoresistance in lung cancer cells. J Nanobiotechnology 15: 87, 2017

90. Warburg O: On respiratory impairment in cancer cells Science 124: 269-270, 1956.

91. Kim JW and Dang CV: Cancer's molecular sweet tooth and the Warburg effect. Cancer Res 66: 8927-8930, 2006.

92. Chen Z, Lu W, Garcia-Prieto C and Huang P: The Warburg effect and its cancer therapeutic implications. J Bioenerg Biomembr 39: 267-274, 2007.

93. Wagner W, Ciszewski WM and Kania KD: L- and D-lactate enhance DNA repair and modulate the resistance of cervical carcinoma cells to anticancer drugs via histone deacetylase inhibition and hydroxycarboxylic acid receptor 1 activation. Cell Commun Signal 13: 36, 2015

94. Granja S, Tavares-Valente D, Queiros O and Baltazar F: Value of $\mathrm{pH}$ regulators in the diagnosis, prognosis and treatment of cancer. Semin Cancer Biol 43: 17-34, 2017.

95. Doyen J, Parks SK, Marcie S, Pouyssegur J and Chiche J: Knock-down of hypoxia-induced carbonic anhydrases IX and XII radiosensitizes tumor cells by increasing intracellular acidosis. Front Oncol 2: 199, 2013

96. Dubois L, Peeters S, Lieuwes NG, Geusens N, Thiry A Wigfield S, Carta F, McIntyre A, Scozzafava A, Dogné JM, et al: Specific inhibition of carbonic anhydrase IX activity enhances the in vivo therapeutic effect of tumor irradiation. Radiother Oncol 99: 424-431, 2011.

97. Betof AS, Rabbani ZN, Hardee ME, Kim SJ, Broadwater G Bentley RC, Snyder SA, Vujaskovic Z, Oosterwijk E, Harris LN, et al: Carbonic anhydrase IX is a predictive marker of doxorubicin resistance in early-stage breast cancer independent of HER2 and TOP2A amplification. Br J Cancer 106: 916-922, 2012.

98. Aomatsu N, Yashiro M, Kashiwagi S, Kawajiri H, Takashima T, Ohsawa M, Wakasa $\mathrm{K}$ and Hirakawa K: Carbonic anhydrase 9 is associated with chemosensitivity and prognosis in breast cancer patients treated with taxane and anthracycline. BMC Cancer 14 400, 2014.

99. Rauch C: On the relationship between drug's size, cell membrane mechanical properties and high levels of multi drug resistance: A comparison to published data. Eur Biophys J 38: 537-546, 2009

100. Perez-Sayans M, Somoza-Martin JM, Barros-Angueira F, Diz PG, Rey JM and Garcia-Garcia A: Multidrug resistance in oral squamous cell carcinoma: The role of vacuolar ATPases. Cancer Lett 295: 135-143, 2010

101. Larsen AK, Escargueil AE and Skladanowski A: Resistance mechanisms associated with altered intracellular distribution of anticancer agents. Pharmacol Ther 85: 217-229, 2000.
102. Le Floch R, Chiche J, Marchiq I, Naiken T, Ilc K, Murray CM Critchlow SE, Roux D, Simon MP and Pouysségur J: CD147 subunit of lactate $/ \mathrm{H}^{+}$symporters MCT1 and hypoxia-inducible MCT4 is critical for energetics and growth of glycolytic tumors. Proc Natl Acad Sci USA 108: 16663-16668, 2011.

103. Boidot R, Vegran F, Meulle A, Le Breton A, Dessy C, Sonveaux P, Lizard-Nacol S and Feron O: Regulation of monocarboxylate transporter MCT1 expression by p53 mediates inward and outward lactate fluxes in tumors. Cancer Res 72: 939-948, 2012

104. Saenz-de-Santa-Maria I, Bernardo-Castineira C, Secades P, Bernaldo-de-Quirós S, Rodrigo JP, Astudillo A and Chiara MD Clinically relevant HIF-1 $\alpha$-dependent metabolic reprogramming in oropharyngeal squamous cell carcinomas includes coordinated activation of CAIX and the miR-210/ISCU signaling axis, but not MCT1 and MCT4 upregulation. Oncotarget 8 : $13730-13746,2017$

105. Draoui N, Schicke O, Seront E, Bouzin C, Sonveaux P, Riant O and Feron O: Antitumor activity of 7-aminocarboxycoumarin derivatives, a new class of potent inhibitors of lactate influx but not efflux. Mol Cancer Ther 13: 1410-1418, 2014

106. Li QX, Zhang P, Liu F, Wang XZ, Li L, Wang ZK, Jiang CC, Zheng HL and Liu H: Monocarboxylate transporter 1 enhances the sensitivity of breast cancer cells to 3-bromopyruvate in vitro. Nan Fang Yi Ke Da Xue Xue Bao 37: 588-593, 2017 (In Chinese).

107. Pisarsky L, Bill R, Fagiani E, Dimeloe S, Goosen RW, Hagmann J, Hess C and Christofori G: Targeting metabolic symbiosis to overcome resistance to anti-angiogenic therapy. Cell Rep 15: 1161-1174, 2016

108. Khammanivong A, Saha J, Spartz AK, Sorenson BS, Bush AG Korpela DM, Gopalakrishnan R, Jonnalagadda S, Mereddy VR, O'Brien TD, et al: A novel MCT1 and MCT4 dual inhibitor reduces mitochondrial metabolism and inhibits tumour growth of feline oral squamous cell carcinoma. Vet Comp Oncol 8: 324-341, 2020

109. Andreucci E, Ruzzolini J, Peppicelli S, Bianchini F, Laurenzana A, Carta F, Supuran CT and Calorini L: The carbonic anhydrase IX inhibitor SLC-0111 sensitises cancer cells to conventional chemotherapy. J Enzyme Inhib Med Chem 34: 117-123, 2019.

110. Tan EY, Yan M, Campo L, Han C, Takano E, Turley H, Candiloro I, Pezzella F, Gatter KC, Millar EK, et al: The key hypoxia regulated gene CAIX is upregulated in basal-like breast tumours and is associated with resistance to chemotherapy. $\mathrm{Br} J$ Cancer 100: 405-411, 2009.

111. Zheng G, Peng C, Jia X, Gu Y, Zhang Z, Deng Y, Wang C, Li N, Yin J, Liu X, et al: ZEB1 transcriptionally regulated carbonic anhydrase 9 mediates the chemoresistance of tongue cancer via maintaining intracellular $\mathrm{pH}$. Mol Cancer 14: 84, 2015.

112. Takahashi E, Abe J and Berk BC: Angiotensin II stimulates p90rsk in vascular smooth muscle cells. A potential $\mathrm{Na}(+)-\mathrm{H}^{+}$ exchanger kinase. Circ Res 81: 268-273, 1997.

113. Altaf E, Huang X, Xiong J, Yang X, Deng X, Xiong M, Zhou L, Pan S, Yuan W, Li X, et al: NHE1 has a notable role in metastasis and drug resistance of T-cell acute lymphoblastic leukemia. Oncol Lett 14: 4256-4262, 2017.

114. Chen Q, Liu Y, Zhu XL, Feng F, Yang H and Xu W: Increased NHE1 expression is targeted by specific inhibitor cariporide to sensitize resistant breast cancer cells to doxorubicin in vitro and in vivo. BMC Cancer 19: 211, 2019.

115. Paskeviciute $M$ and Petrikaite V: Overcoming transporter-mediated multidrug resistance in cancer: Failures and achievements of the last decades. Drug Deliv Transl Res 9: 379-393, 2019

116. Park S, Chang CY, Safi R, Liu X, Baldi R, Jasper JS Anderson GR, Liu T, Rathmell JC, Dewhirst MW, et al: ERR $\alpha$-Regulated lactate metabolism contributes to resistance to targeted therapies in breast cancer. Cell Rep 15: 323-335, 2016.

117. Yu T, Yang G, Hou Y, Tang X, Wu C, Wu XA, GuoL,ZhuQ, LuoH, $\mathrm{Du}$ YE, et al: Cytoplasmic GPER translocation in cancer-associated fibroblasts mediates cAMP/PKA/CREB/glycolytic axis to confer tumor cells with multidrug resistance. Oncogene 36: 2131-2145, 2017

118. Kalbasi A and Ribas A: Tumour-intrinsic resistance to immune checkpoint blockade. Nat Rev Immunol 20: 25-39, 2020

119. Garcia-Diaz A, Shin DS, Moreno BH, Saco J, Escuin-Ordinas H, Rodriguez GA, Zaretsky JM, Sun L, Hugo W, Wang X, et al: Interferon receptor signaling pathways regulating PD-L1 and PD-L2 expression. Cell Rep 19: 1189-1201, 2017. 
120.Liang X, Fu C, Cui W, Ober-Blöbaum JL, Zahner SP, Shrikant PA, Clausen BE, Flavell RA, Mellman I and Jiang A: $\beta$-catenin mediates tumor-induced immunosuppression by inhibiting cross-priming of $\mathrm{CD} 8^{+} \mathrm{T}$ cells. J Leukoc Biol 95: 179-190, 2014.

121. Peng W, Chen JQ, Liu C, Malu S, Creasy C, Tetzlaff MT, Xu C, McKenzie JA, Zhang C, Liang X, et al: Loss of PTEN promotes resistance to T cell-mediated immunotherapy. Cancer Discov 6: 202-216, 2016

122. Gao J, Shi LZ, Zhao H, Chen J, Xiong L, He Q, Chen T, Roszik J, Bernatchez C, Woodman SE, et al: Loss of IFN-Y pathway genes in tumor cells as a mechanism of resistance to anti-CTLA-4 therapy. Cell 167: 397-404.e9, 2016.

123. Pitroda SP, Wakim BT, Sood RF, Beveridge MG, Beckett MA MacDermed DM, Weichselbaum RR and Khodarev NN: STAT1-dependent expression of energy metabolic pathways links tumour growth and radioresistance to the warburg effect BMC Med 7: 68, 2009

124. Poli V and Camporeale A: STAT3-mediated metabolic reprograming in cellular transformation and implications for drug resistance. Front Oncol 5: 121, 2015.

125.Cascone T, McKenzie JA, Mbofung RM, Punt S, Wang Z, Xu C, Williams LJ, Wang Z, Bristow CA, Carugo A, et al: Increased tumor glycolysis characterizes immune resistance to adoptive T cell therapy. Cell Metab 27: 977-987. e4, 2018.

126. Sacchi S, Federico M, Vitolo U, Boccomini C, Vallisa D, Baldini L, Petrini M, Rupoli S, Di Raimondo F, Merli F, et al: Clinical activity and safety of combination immunotherapy with IFN-alpha $2 \mathrm{a}$ and Rituximab in patients with relapsed low grade non-Hodgkin's lymphoma. Haematologica 86: 951-958, 2001.

127. Davis TA, Maloney DG, Grillo-Lopez AJ, White CA, Williams ME, Weiner GJ, Dowden $S$ and Levy $R$ : Combination immunotherapy of relapsed or refractory low-grade or follicular non-Hodgkin's lymphoma with rituximab and interferon-alpha-2a. Clin Cancer Res 6 : 2644-2652, 2000.

128. Rosenberg SA, Lotze MT, Yang JC, Linehan WM, Seipp C, Calabro S, Karp SE, Sherry RM, Steinberg S and White DE: Combination therapy with interleukin-2 and alpha-interferon for the treatment of patients with advanced cancer. J Clin Oncol 7: 1863-1874, 1989.

129. Magalhaes I, Yogev O, Mattsson J and Schurich A: The metabolic profile of tumor and virally infected cells shapes their microenvironment counteracting T cell immunity. Front Immunol 10: 2309, 2019.

130. Pate KT, Stringari C, Sprowl-Tanio S, Wang K, TeSlaa T, Hoverter NP, McQuade MM, Garner C, Digman MA Teitell MA, et al: Wnt signaling directs a metabolic program of glycolysis and angiogenesis in colon cancer. EMBO J 33: 1454-1473, 2014.

131. Yang L, Perez AA, Fujie S, Warden C, Li J, Wang Y, Yung B, Chen YR, Liu X, Zhang $\mathrm{H}$, et al: Wnt modulates MCL1 to control cell survival in triple negative breast cancer. BMC Cancer 14: 124, 2014

132. Sprowl-Tanio S, Habowski AN, Pate KT, McQuade MM, Wang K, Edwards RA, Grun F, Lyou Y and Waterman ML: Lactate/pyruvate transporter MCT-1 is a direct Wnt target that confers sensitivity to 3-bromopyruvate in colon cancer. Cancer Metab 4: 20, 2016.

133. Feng M, Jin JQ, Xia L, Xiao T, Mei S, Wang X, Huang X, Chen J, Liu M, Chen C, et al: Pharmacological inhibition of $\beta$-catenin/BCL9 interaction overcomes resistance to immune checkpoint blockades by modulating $\mathrm{T}_{\text {reg }}$ cells. Sci Adv 5: eaau5240, 2019.

134. George S, Miao D, Demetri GD, Adeegbe D, Rodig SJ, Shukla S, Lipschitz M, Amin-Mansour A, Raut CP, Carter SL, et al: Loss of PTEN is associated with resistance to Anti-PD-1 checkpoint blockade therapy in metastatic uterine leiomyosarcoma. Immunity 46: 197-204, 2017

135. Ramapriyan R, Caetano MS, Barsoumian HB, Mafra ACP, Zambalde EP, Menon H, Tsouko E, Welsh JW and Cortez MA: Altered cancer metabolism in mechanisms of immunotherapy resistance. Pharmacol Ther 195: 162-171, 2019.

136. Jabbarzadeh Kaboli P, Salimian F, Aghapour S, Xiang S, Zhao Q, Li M, Wu X, Du F, Zhao Y, Shen J, et al: Akt-targeted therapy as a promising strategy to overcome drug resistance in breast cancer-A comprehensive review from chemotherapy to immunotherapy. Pharmacol Res 156: 104806, 2020.
137. Blagden SP, Hamilton AL, Mileshkin L, Wong S, Michael A, Hall M, Goh JC, Lisyanskaya AS, DeSilvio M, Frangou E, et al: Phase IB dose escalation and expansion study of AKT inhibitor afuresertib with carboplatin and paclitaxel in recurrent platinum-resistant ovarian cancer. Clin Cancer Res 25: 1472-1478, 2019.

138. Tammela T, Sanchez-Rivera FJ, Cetinbas NM, Wu K, Joshi NS, Helenius K, Park Y, Azimi R, Kerper NR, Wesselhoeft RA, et al: A Wnt-producing niche drives proliferative potential and progression in lung adenocarcinoma. Nature 545: 355-359, 2017

139. de Bono JS, De Giorgi U, Rodrigues DN, Massard C, Bracarda S, Font A, Arranz Arija JA, Shih KC, Radavoi GD, Xu N, et al: Randomized phase II study evaluating Akt blockade with ipatasertib, in combination with abiraterone, in patients with metastatic prostate cancer with and without PTEN loss. Clin Cancer Res 25: 928-936, 2019.

140. Kunkl M, Sambucci M, Ruggieri S, Amormino C, Tortorella C, Gasperini C, Battistini L and Tuosto L: CD28 autonomous signaling Up-regulates $\mathrm{C}$-Myc expression and promotes glycolysis enabling inflammatory $\mathrm{T}$ cell responses in multiple sclerosis. Cells 8: 575, 2019.

141. Chen F, Chen J, Yang L, Liu J, Zhang X, Zhang Y, Tu Q, Yin D, Lin D, Wong PP, et al: Extracellular vesicle-packaged HIF-1 $\alpha$-stabilizing lncRNA from tumour-associated macrophages regulates aerobic glycolysis of breast cancer cells. Nat Cell Biol 21: 498-510, 2019.

142. Xie G, Liu Y, Yao Q, Zheng R, Zhang L, Lin J, Guo Z, Du S, Ren C, Yuan Q and Yuan Y: Hypoxia-induced angiotensin II by the lactate-chymase-dependent mechanism mediates radioresistance of hypoxic tumor cells. Sci Rep 7: 42396, 2017.

143. Xie G, Cheng T, Lin J, Zhang L, Zheng J, Liu Y, Xie G, Wang B and Yuan Y: Local angiotensin II contributes to tumor resistance to checkpoint immunotherapy. J Immunother Cancer 6: 88, 2018.

144. Fischer K, Hoffmann P, Voelk1 S, Meidenbauer N, Ammer J, Edinger M, Gottfried E, Schwarz S, Rothe G, Hoves S, et al: Inhibitory effect of tumor cell-derived lactic acid on human $\mathrm{T}$ cells. Blood 109: 3812-3819, 2007

145. Ohashi T, Akazawa T, Aoki M, Kuze B, Mizuta K, Ito Y and Inoue N: Dichloroacetate improves immune dysfunction caused by tumor-secreted lactic acid and increases antitumor immunoreactivity. Int J Cancer 133: 1107-1118, 2013.

146. Warburg O: On the origin of cancer cells. Science 123: 309-314, 1956.

147. Bosc C, Selak MA and Sarry JE: Resistance is futile: Targeting mitochondrial energetics and metabolism to overcome drug resistance in cancer treatment. Cell Metab 26: 705-707, 2017.

148. Alexa-Stratulat T, Pesic M, Gasparovic AC, Trougakos IP and Riganti C: What sustains the multidrug resistance phenotype beyond $\mathrm{ABC}$ efflux transporters? Looking beyond the tip of the iceberg. Drug Resist Updat 46: 100643, 2019.

149. Roth KG, Mambetsariev I, Kulkarni P and Salgia R: The mitochondrion as an emerging therapeutic target in cancer. Trends Mol Med 26: 119-134, 2020.

150. Farge T, Saland E, de Toni F, Aroua N, Hosseini M, Perry R, Bosc C, Sugita M, Stuani L, Fraisse M, et al: Chemotherapy-resistant human acute myeloid leukemia cells are not enriched for leukemic stem cells but require oxidative metabolism. Cancer Discov 7: 716-735, 2017.

151. MignecoG, Whitaker-Menezes D, Chiavarina B, Castello-Cros R, Pavlides S, Pestell RG, Fatatis A, Flomenberg N, Tsirigos A, Howell A, et al: Glycolytic cancer associated fibroblasts promote breast cancer tumor growth, without a measurable increase in angiogenesis: Evidence for stromal-epithelial metabolic coupling. Cell Cycle 9: 2412-2422, 2010

152. Ricci F, Brunelli L, Affatato R, Chilà R, Verza M, Indraccolo S, Falcetta F, Fratelli M, Fruscio R, Pastorelli R and Damia G: Overcoming platinum-acquired resistance in ovarian cancer patient-derived xenografts. Ther Adv Med Oncol 11: 1758835919839543,2019

153. Wu L, Zhao J, Cao K, Liu X, Cai H, Wang J, Li W and Chen Z: Oxidative phosphorylation activation is an important characteristic of DOX resistance in hepatocellular carcinoma cells. Cell Commun Signal 16: 6, 2018

154. Lee KM, Giltnane JM, Balko JM, Schwarz LJ, Guerrero-Zotano AL, Hutchinson KE, Nixon MJ, Estrada MV, Sánchez V, Sanders ME, et al: MYC and MCL1 cooperatively promote chemotherapy-resistant breast cancer stem cells via regulation of mitochondrial oxidative phosphorylation. Cell Metab 26: 633-647.e7, 2017. 
155. Chen CL, Uthaya Kumar DB, Punj V, Xu J, Sher L, Tahara SM, Hess $S$ and Machida K: NANOG metabolically reprograms tumor-initiating stem-like cells through tumorigenic changes in oxidative phosphorylation and fatty acid metabolism. Cell Metab 23: 206-219, 2016.

156. Andreucci E, Pietrobono S, Peppicelli S, Ruzzolini J, Bianchini F, Biagioni A, Stecca B and Calorini L: SOX2 as a novel contributor of oxidative metabolism in melanoma cells. Cell Commun Signal 16: 87, 2018.
157. Zhao Y, Butler EB and Tan M: Targeting cellular metabolism to improve cancer therapeutics. Cell Death Dis 4: e532, 2013.

158. Choi HJ, Jhe YL, Kim J, Lim JY, Lee JE, Shin MK and Cheong JH: FoxM1-dependent and fatty acid ox idation-mediated ROS modulation is a cell-intrinsic drug resistance mechanism in cancer stem-like cells. Redox Biol 36: 101589, 2020. 